\title{
Orthostatic Hypotension in a Complex Clinical Setting Use of the Heart Rate Increase/Systolic Blood Pressure Decrease Ratio as a
}

\section{Diagnostic Aid}

\section{Jochanan E. Naschitz}

Bait Balev Nesher and The Ruth and Bruce Rappaport Faculty of Medicine, Technion, Israel Institute of Technology, Haifa, Israel.

E mail: Naschitz@ technion.ac.il

*Corresponding author: Jochanan E. Naschitz, Bait Balev Nesher and The Ruth and Bruce Rappaport Faculty of Medicine, Technion, Israel Institute of Technology, Haifa, Israel.

Received Date: July 07, 2020; Accepted Date: July 15, 2020; Published Date: July $28,2020$.

Citation: Jochanan E. Naschitz, (2020) Orthostatic Hypotension in a Complex Clinical Setting Use of the Heart Rate Increase/Systolic Blood Pressure Decrease Ratio as a Diagnostic Aid. J Clinical Case Reports and Studies, 1(3): Doi: 10.31579/2690-8808/015

Copyright: (c) 2020. Jochanan E. Naschitz. This is an open-access article distributed under the terms of the Creative Commons Attribution License, which permits unrestricted use, distribution, and reproduction in any medium, provided the original author and source are credited.

\section{Abstract}

A simple bedside test to distinguish neurogenic from non-neurogenic causes of orthostatic hypotension $(\mathrm{OH})$ is the ratio of heart rate increase during $\mathrm{OH}$ to the simultaneous decrease in systolic blood pressure (SBP), i.e. the $\Delta \mathrm{HR} / \Delta \mathrm{SBP}$ ratio. In a patient suffering from persistent $\mathrm{OH}$ we monitored the $\Delta \mathrm{HR} / \Delta \mathrm{SBP}$ ratio to aid with a targeted therapy. During a six-week period four pairs of postural tests were performed, one in the fasting and the other in the postprandial state. Inconsistency of the $\Delta \mathrm{HR} / \Delta \mathrm{SBP}$ ratio under the patient's apparently stable clinical condition was confusing. So, the $\Delta \mathrm{HR} / \Delta \mathrm{SBP}$ ratio did help in taking therapeutic decisions.

Keywords: orthostatic hypotension; systolic blood pressure; Diagnostic Aid

\section{Introduction}

A simple bedside test to distinguish neurogenic from non-neurogenic causes of orthostatic hypotension $(\mathrm{OH})$ is the ratio of heart rate increase to the simultaneous decrease in systolic blood pressure during $\mathrm{OH}$ ( $\triangle H R / \triangle S B P$ ratio) [1]. Since the heart rate response to hypotension is pronounced in patients with non-neurogenic $O H$ but is blunted in those with efferent baroreflex failure, a $\triangle H R / \triangle S B P$ ratio $<0.5$ indicates baroreflex failure and is considered to provide a sensitive and specific cutoff value during active standing [2]. In a patient who suffered from persistent $\mathrm{OH}$ we sought help for therapeutic decisions by repeatedly observing the $\triangle H R / \triangle S B P$ ratio.

\section{Case history}

A 72-year-old man was admitted for post-acute care, having recovered from complications of elective surgery. He was a longtime hypertensive with the blood pressure (BP) fairly controlled on valsartan treatment. Eight years ago, he was diagnosed with carcinoma of the rectum and underwent anterior resection with colostomy, followed by radiation therapy. There was no recurrence of carcinoma. He was physically and mentally fit and independent in daily activities, until he recently underwent surgery for closure of the colostomy and repair of peristomal hernia. Surgery was complicated by perforation of the small bowel, peritonitis, shock, acute renal failure, and liver failure. A large segment of the small bowel needed to be resected with 1.4 meters left. An ileostomy was formed. After the patient's condition stabilized, he was transferred to our institution for rehabilitation. The ileostomy output was roughly $3000 \mathrm{ml}$, the diuresis $2000-2500 \mathrm{ml}$. The patient was alert and conscious. The vital signs were normal, inclusive the body temperature, supine BP, heart rate (HR), and oxygen saturation. However, when trying to sit the patient fainted repeatedly, the BP dropping within a minute as low as SBP $57 \mathrm{mmHg}$. Large volumes of intravenous fluids were administered, and electrolytes as needed to correct deficiencies. The diet was tailored to match osmotic diarrhea and malabsorption. Loperamide $16 \mathrm{mg}$ /day was administered to reduce the intestinal transit time and improve absorption. When the patient's condition further improved, he could be weaned from parenteral fluids. He had a good appetite, was sitting the on a chair most of the day, was walking without assistance 50 meters three times a day. He had gained weight without developing edema. The fecal output through ileostomy decreased to $1100-1300 \mathrm{ml}$ (versus 3000 on admission). The diuresis remained close to $2000 \mathrm{ml}$. The hematocrit, serum $\mathrm{Na}$ and the eGFR were within the normal range. However, asymptomatic $\mathrm{OH}$ remained. Currently the patient's medications were loperamide Tab 16 mg/day, magnesium citrate Tab 200 mg, calcium carbonate Tab $1800 \mathrm{mg}$, vitamin D3 Tb $2000 \mathrm{U}$, and famotidine Tab $40 \mathrm{mg}$. The fluid balance was supervised daily. Postural tests were done weakly, along with monitoring laboratory markers of dehydration (hematocrit, serum Na, serum osmolality, eGFR). Since hypovolemia and deconditioning had resolved but $\mathrm{OH}$ persisted we considered that critical illness neuropathy might be implicated in the causation of $\mathrm{OH}[3,4]$. However, there was no muscle weakness, the deep tendon reflexes were normal, and there was no sensory loss. The patient postponed electrophysiologic testing in the face of the corona epidemic. 


\section{Methods}

The supine-to-standing postural test is standardized and validated, though, reproducibility is far from optimal; no better test exists [5]. According to the protocol the BP and HR are recorded after 15 minutes of rest in the supine position, 5 times, at one-minute intervals. Next, the patient stands up and measurements are taken with the cuffed arm supported at heart level at one-minute intervals for another 5 minutes. The procedure is aborted for safety reasons if the BP drops precipitously or symptoms of presyncope evolve. We measured the patient's BP on his right arm at heart level, using a Spot Vital SignsR validated automatic oscillometric device (Welch Allyn Inc. Corporate, NY 13153-0220 USA). The HR was recorded by pulse oximetry on the other arm. At awakening the patient was instructed to drink $500 \mathrm{~mL}$ water and apply he fitted footto-groin compression garments. First at 8 a.m. in the fasting state a supineto-standing postural test was performed. About 60 minutes later, after the patient had eaten breakfast (equivalent to approximately $900 \mathrm{kcal}$ ), the supine to standing postural test was repeated. $\mathrm{OH}$ was diagnosed as a fall in systolic $\mathrm{BP}$ of $\geq 20 \mathrm{mmHg}$ and/or diastolic $\mathrm{BP}$ of $\geq 10 \mathrm{mmHg}$ within 3 minutes of standing [6].

Postprandial hypotension (PPH) was diagnosed as a decrease in SBP of at least $20 \mathrm{mmHg}$ within two hours after a meal (7). $\triangle H R / \triangle S B P$ ratio during $\mathrm{OH}$ was computed related to SBP nadir. The $\Delta \mathrm{HR} / \triangle \mathrm{SBP}$ is the ratio of the increase in heart rate (beats per minute) to the decrease in SBP (millimeters of mercury). $\Delta \mathrm{HR} / \triangle \mathrm{SBP}$ ratio $<0.5$ indicates neurogenic $\mathrm{OH}$, distinguishing between neurogenic from non-neurogenic $\mathrm{OH}[1,2]$.

\section{Results}

We analyzed paired postural tests completed through June - July when the patient was clinically stable, the fluid input and output were balanced, the body weight was stable, and laboratory markers showed no evidence of dehydration. In all instances, $\mathrm{OH}$ occurred within the first two minutes of standing, was asymptomatic, and improved subsequently, as illustrated in Figures 1 and 2.

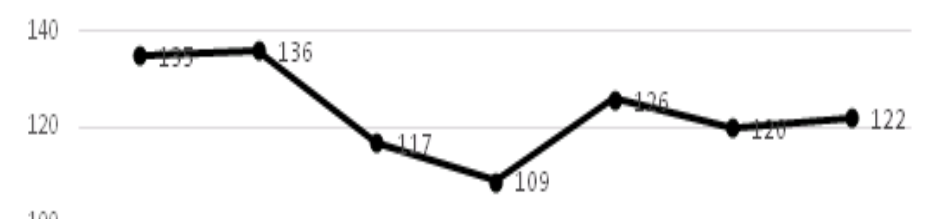

100

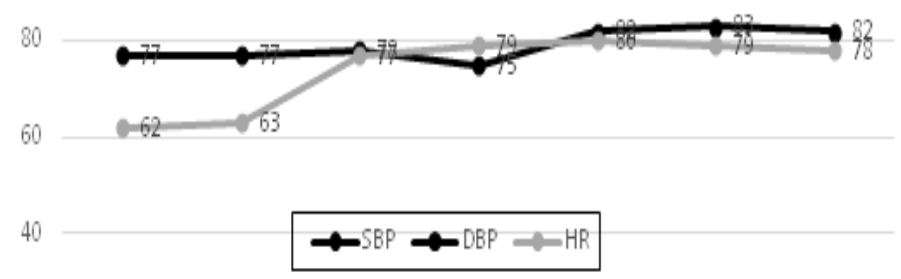

20

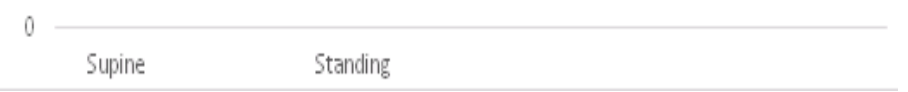

Figure 1. Postural test at 8.15 a.m. in the fasting state. $\mathrm{OH}$ was mild and transient. The $\Delta \mathrm{HR} / \Delta \mathrm{SBP}$ was 0.59 .

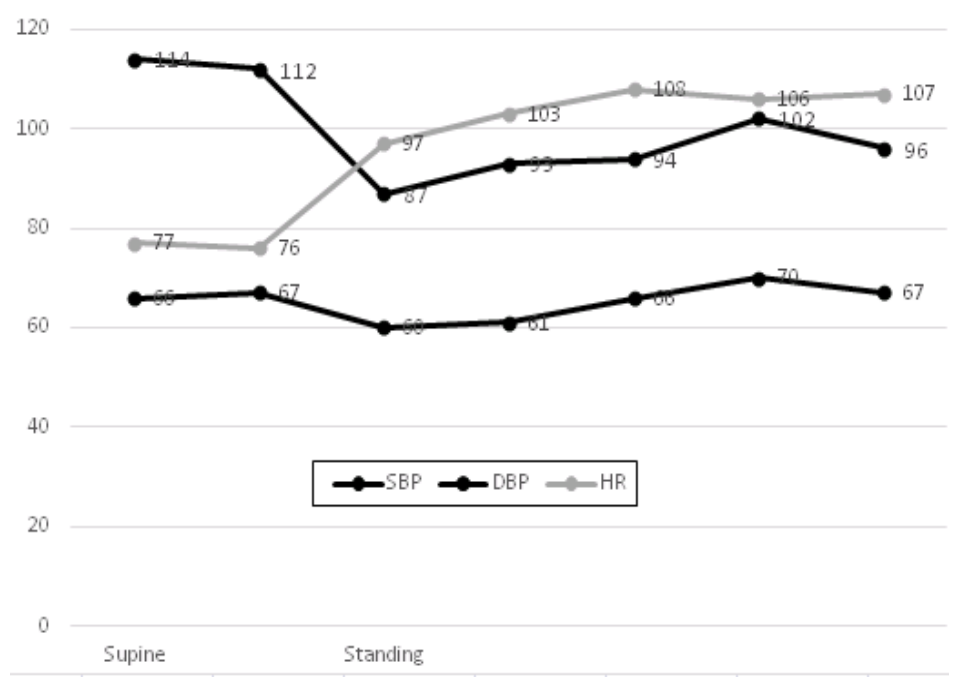

Figure 2. Postural test at 9.30 a.m., after breakfast, next to the test illustrated in Figure 1. The supine BP was lower and the HR higher than in the fasting state. The BP decline when standing was deeper. The patient remained free of symptoms. The $\Delta \mathrm{HR} / \Delta \mathrm{SBP}$ was 0.84 .

Four pairs of postural tests were available for analysis; the $\Delta \mathrm{HR} / \Delta \mathrm{SBP}$ ratios are shown in Table 1 . With reference to the $\Delta \mathrm{HR} / \Delta \mathrm{SBP}<0.5$ threshold, indicating neurogenic $\mathrm{OH}$, there was inconsistency of the results both in the fasting and in the postprandial state.

\begin{tabular}{|l|l|}
\hline$\Delta H R / \Delta S B P$ Fasting & $\Delta H R / \Delta S B P$ Postprandial \\
\hline 0.57 & 0.37 \\
\hline 0.71 & 0.85 \\
\hline 0.42 & 1 \\
\hline 0.59 & 0.84 \\
\hline
\end{tabular}

Table 1. $\Delta \mathrm{HR} / \Delta \mathrm{SBP}$ ratios under $\mathrm{OH}$ in the fasting and subsequent postprandial state

\section{Discussion}

Postural BP homeostasis depends on the normal functioning of the autonomic nervous system, euvolemia, anatomic and functional integrity of the heart and blood vessels, the postprandial state, and the ambient temperature. When healthy individuals stand $10 \%$ to $15 \%$ of the blood is pooled in the legs and lower abdomen, thereby diminishing the venous return, with ensuing decline of cardiac output and BP. An adequate homeostatic response to the decrease in BP occurs by activation of baroreceptors, reflex sympathetic stimulation that prompts vasoconstriction, tachycardia, and an enhanced cardiac contractility. When the homeostatic mechanisms are normally functioning, there may be but a slight fall in the SBP as a person stands up, associated with a slight rise in diastolic BP and a mild increase in HR. Failure of one or the other compensatory mechanism may cause $\mathrm{OH}$, i.e. a disproportionate fall in BP occurring early after standing up [8]. Common causes of $\mathrm{OH}$ are medications (diuretics, nitrates, antihypertensives, tricyclic antidepressants), hypovolemia (dehydration, post obstructive polyuria, bleeding either overt or occult, blood pooling in large varicose veins), and autonomic neuropathies either primary (primary autonomic failure, 
multiple system atrophy, Parkinson's disease) or secondary (in diabetes mellitus, chronic renal failure, chronic liver disease, alcohol-induced, vitamin B12 deficiency, Guillain-Barre syndrome, paraneoplastic, etc) $[9,10]$. In many instances, the cause of $\mathrm{OH}$ is obvious. In other instances, several mechanisms may be involved, and identifying the major mechanism responsible for $\mathrm{OH}$ may be challenging. An aid in such situation is provided by the HR response under postural challenge: it is blunted in the presence of baroreflex failure contrasting with the pronounced acceleration of the HR in non-neurogenic $\mathrm{OH}$. The $\Delta \mathrm{HR} / \triangle \mathrm{SBP}$ has been reported to distinguish accurately neurogenic from non-neurogenic $\mathrm{OH}[2]$. In the proposito, six out of eight tests produced $\Delta \mathrm{HR} / \Delta \mathrm{SBP}>0.5$, that is consistent with hypovolemia. Yet, the analysis was limited to a period when all clinical and laboratory parameters were inconsistent with dehydration [11]. Also, limited to the time of the study, $\mathrm{OH}$ could not be attributed to additional conditions displaying a $\Delta \mathrm{HR} / \Delta \mathrm{SBP}>0.5$. Indeed, the patient was not taking medications known to cause $\mathrm{OH}$; adrenal insufficiency has been excluded by normal values of basal and stimulated cortisol; the patient had no varicose veins; there was no evidence of a neoplasia on recent comprehensive investigation. In the proposito, two tests showed a blunted HR response $(\Delta \mathrm{HR} / \Delta \mathrm{SBP}$ $<0.5)$, contrasting with the pronounced HR acceleration in six instances. Inconsistency of the HR response to hypotension was confusing and did not lend support to a targeted therapy.

Other questions arose while caring for the patient, only to be listed here. First, was critical illness neuropathy part of the problem, contributing to $\mathrm{OH}$ ? [12] Second, was postprandial splanchnic blood pooling affected by the extensive resection of small and large bowel? [13]. these are important issues but are marginal to the aim of the present study that was to substantiate the role of $\Delta \mathrm{HR} / \Delta \mathrm{SBP}$ for evaluation of $\mathrm{OH}$ in a complex clinical situation. Inconsistency of the HR response to hypotension did not support a targeted therapy based on the $\Delta \mathrm{HR} / \Delta \mathrm{SBP}$ ratio in this patient's complex clinical situation. For answering the query there is need for more studies and the covering a wide spectrum of clinical settings.

\section{References}

1. Kaufmann H, Norcliffe-Kaufmann L, Palma J-A. (2020). Baroreflex dysfunction. N Engl J Med. 382:163-178.
2. Norcliffe-Kaufmann L. Horacio Kaufmann H, Palma J-A, Shibao CA, Biagionii I, et al. (2018). Orthostatic heart rate changes in patients with autonomic failure caused by neurodegenerative synucleinopathies. Ann Neurol 83:522-531.

3. Allen BB, Charles JA, Papadopoulos E, Avila EK. (2016). Neurogenic orthostatic hypotension with critical illness neuropathy treated with Droxidopa. Auton Neurosci. 198:8-9.

4. Latronico N, Filosto M, Fagoni N, Gheza L, Guarneri B, et al. (2013). Small nerve fiber pathology in critical illness. PLoS ONE. 8:e75696.

5. Cooke J, Carew S, O'Connor M, Costelloe A, Sheehy T, Lyons D. (2009). Sitting and standing blood pressure measurements are not accurate for the diagnosis of orthostatic hypotension. QJM. 102:335-339.

6. Freeman R, Wieling W, Axelrod FB, Benditt DG, Benarroch E, et al. (2011). Consensus statement on the definition of orthostatic hypotension, neurally mediated syncope and the postural tachycardia syndrome. Clin Auton Res. 21:69-72.

7. Madden KM, Feldman B, Meneilly GS. (2019). Blood pressure measurement and the prevalence of postprandial hypotension. Clin Invest Med. 42:E39-E46.

8. Naschitz JE, Rosner I. (2007). Orthostatic hypotension: framework of the syndrome. Postgrad Med J. 83:568-74.

9. Lagro J, Meel-van den Abeelen A, de Jong DL, Schalk BW, Olde Rikkert MG et al. (2013). Geriatric hypotensive syndromes are not explained by cardiovascular autonomic dysfunction alone. J Gerontol A Biol Sci Med Sci. 68:581-589.

10. Frith J, Newton JL, Parry SW. (2014). Measuring and defining orthostatic hypotension in the older person. Age and Ageing. 43:168-170.

11. Hooper L, Abdelhamid A, Attreed NJ, Campbell WW,Channell AM, Chassagne P, et al. (2015). Clinical symptoms, signs and tests for identification of impending and current waterloss dehydration in older people. Cochrane Database Syst Rev. (4):CD009647.

12. Zifko UA. (2000). Long-term outcome of critical illness polyneuropathy. Muscle Nerve Suppl. 9:S49-S52.

13. Jansen RWMM, Lipsitz LA. (1995). Postprandial Hypotension: Epidemiology, pathophysiology, and clinical management. Ann Intern Med. 22:286-295
This work is licensed under Creative Commons Attribution 4.0 License
Ready to submit your research? Choose Auctores and benefit from:

* fast, convenient online submission

* rigorous peer review by experienced research in your field

* rapid publication on acceptance

* authors retain copyrights

* unique DOI for all articles

* immediate, unrestricted online access

At Auctores, research is always in progress.

Learn more https://www.auctoresonline.org/journals/journal-ofclinical-case-reports-and-studies 